\title{
Have you looked for "stranger things" in your automated PET dose dispensing system? A process and operators qualification scheme
}

Tristan Martin ${ }^{1}$, Anaïs Moyon ${ }^{2,3,4}$, Cyril Fersing1, Evan Terrier ${ }^{1}$, Aude Gouillet ${ }^{1}$, Fabienne Giraud ${ }^{2}$, Benjamin Guillet ${ }^{1,3,4}$ and Philippe Garrigue ${ }^{1,3,4^{*}}$ (D)

\author{
* Correspondence: philippe. \\ garrigue@univ-amu.fr \\ ${ }^{1}$ Radiopharmacie Hôpital Nord \\ AP-HM, Marseille, France \\ ${ }^{3}$ CERIMED, CNRS 2012, Aix-Marseille \\ Université, Marseille, France \\ Full list of author information is \\ available at the end of the article
}

\begin{abstract}
Background: Many nuclear medicine departments have equipped themselves with automated dispensing systems (ADS) for PET radiopharmaceuticals, in both the operators' and the patients' interests. Whether partially or fully automated, to date there is no marketed ADS representing a true "closed-system". Despite the sterile, injectable nature of ready-to-use radiopharmaceutical drug solutions manipulated by these systems, neither manufacturer's recommendation nor literature report was found about specific qualification of the process' sterility, or about operators' qualification on these dispensing systems. We set up a master plan validation in a radiopharmacy equipped with Trasis Unidose ${ }^{\oplus}$, including: 1) monthly processsimulating media-fill tests and microbiological contamination assessments of the ADS surfaces; 2) initial and periodic qualification of the operators. The microbiological qualification consisted in surface biocontamination assessment on critical zones with Tryptic-Soy agar. The operator qualification consisted in the evaluation of the operators' knowledge and skills for using the ADS.

Results: This study highlighted a minor, handborne microbiological contamination on our first assessment, that corrective actions solved. We therefore decided to brief our operators once a month on microbiological control results, hygiene and good practices, with the support of the present case illustrating the biodecontamination efficiency.

Conclusions: As the automation of PET monodose conditioning process still implies human intervention for material preparation and manual biodecontamination, this study illustrates that initial and periodic qualification of the environment and the conditioning process of ADS, including microbiological qualification and operators' qualification, are needed to meet specifications.
\end{abstract}

Keywords: PET, Radiopharmaceuticals, Qualification, Dispensing system 


\section{Background}

The expanded use of positron-emission tomography (PET) and the intercurrent market authorizations of new PET radiopharmaceuticals implied optimization of their dispensing and administration, in both the operators' and the patients' interests. Since many evidences showed substantial benefits in radioprotection for the operators in terms of dosimetry, many nuclear medicine departments have equipped themselves with automated dispensing systems (ADS) (Covens et al. 2010). Most of the validations found in the literature consist in monitoring physico-medical parameters such as operator dosimetry and accuracy and/or precision of dose activities measurements through dose calibrators (Lecchi et al. 2012; O'Doherty et al. 2014). Whether partially or fully automated, to date there is no marketed ADS representing a true "closed-system". For instance, the Trasis Unidose $^{\circ}$ features a cartridge-filling step which is automatically operated under an open, virtual ISO4.8 system, whose performance is obviously critical for maintaining the microbiological quality of the drug solution. Furthermore, in many radiopharmacies and nuclear medicine departments, the ADS is installed in a non-classified room. Still, despite the sterile, injectable nature of ready-to-use radiopharmaceutical drug solutions manipulated by these systems, neither manufacturer's recommendation nor literature report was found about specific qualification of the process' sterility, or about operators' qualification on these dispensing systems. The basic International Standard Organization (ISO) standards for controlled environment, and the Good Manufacturing Practices (GMP) for production of injectable solutions, still apply to these ADS (ISO n.d.; EudraLex n.d.). A preliminary risk analysis was therefore led in our department prior to the ADS setup and highlighted the microbiological contamination risk could be significant.

The aim of this work was to establish a practical, methodological guideline to help the dozens of Nuclear Medicine centers already equipped with such an ADS (and those intending to) for their routine microbiological qualification and operators' qualification, based on our practical experience.

Inspired by guidance for qualification of small-scale PET radiopharmaceutical synthesis modules, and in respect with the Pharmaceutical Inspection Co-operation Scheme (PIC/S), the European Pharmacopeia and the Food and Drug Administration (FDA) guidance, we set up a master plan validation in a radiopharmacy equipped with Trasis Unidose ${ }^{\bullet}$, including: 1) monthly specific process-simulating media-fill tests (MFT) and microbiological contamination assessments of our ADS surfaces; 2) initial qualification and yearly requalification of the ADS operators (Aerts et al. 2014; PIC/S n.d.; Food and Drug Administration CDER CGMP 2012). The first six-month follow-up period already showed the importance of implementing and long-term pursuing such a process to ensure the continuous performances of the ADS and good practices application.

\section{Methods}

Description of equipment

Qualification was performed on a Unidose ${ }^{\circ}$ dispenser (Trasis) placed in an adapted shielded cabinet equipped with gloves and a shielded glass oculus (Trasis). The cabinet features a main ISO7 compartment hosting the ADS. The multidose PET radiopharmaceutical drug is contained in a closed reservoir, part of the ADS. The individual dose is obtained by cartridge filling, that is weight-controlled operated under an open, local ISO4.8 zone ensured by a High Efficiency Particulate Air (HEPA) filter, inside the ISO7 
compartment. During this critical step, the radiopharmaceutical drug solution leaks from a $0.22 \mu \mathrm{m}$ sterile filter and fills the open cartridge, which is hereafter capped in the same ISO4.8 zone, then measured in a dose calibrator and finally dispensed.

\section{Microbiological validation - surface biocontamination assessment}

Microbiological contamination of surfaces was assessed at the end of a routine PET session on different points (Fig. 1): the carousel in the filling zone (ISO4.8), the gloves (ISO7) and the reservoir surface (ISO7). Through the application of $25 \mathrm{~cm}^{2}$ tryptic-soy

\section{Microbiological validation of Unidose ${ }^{\circledR}$}

\section{Surface biocontamination assessment}

Method: application of $25 \mathrm{~cm}^{2}$ tryptic-soy agar plates before and after biodecontamination on the three points of interest. Incubation at $37^{\circ} \mathrm{C}$ under $5 \% \mathrm{CO}_{2}$ for 5 days.

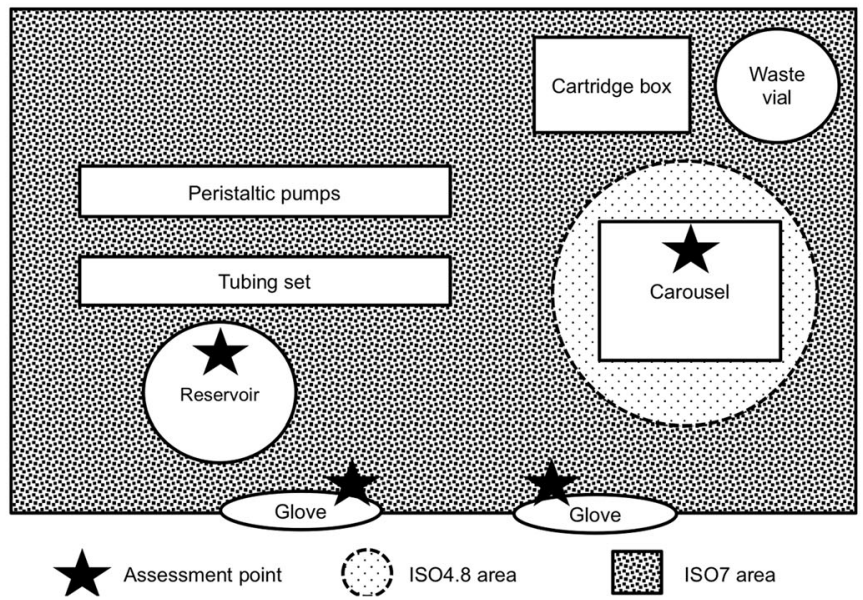

Number of CFU/25 $\mathrm{cm}^{2}$

\begin{tabular}{|c|c|c|c|c|c|}
\hline & Carousel & $\begin{array}{l}\text { Reservoir } \\
\text { surface }\end{array}$ & Gloves & $\begin{array}{c}\text { Negative } \\
\text { control }\end{array}$ & $\begin{array}{l}\text { Positive } \\
\text { control }\end{array}$ \\
\hline Before biodecontamination & & & & & \\
\hline After biodecontamination & & & & & \\
\hline Expected ISO classification & ISO4.8 & ISO7 & ISO7 & \multirow{3}{*}{1} & \multirow{3}{*}{1} \\
\hline Warning level & {$[1 ; 10]$} & {$[25 ; 50]$} & {$[25 ; 50]$} & & \\
\hline Action level & $>10$ & $>50$ & $>50$ & & \\
\hline
\end{tabular}

\section{Media-fill test (when appropriate)}

Method: Cartridges filled with TS broth aseptically transferred to TS broth tubes. Incubation 7 days at room temperature then 7 days at $35^{\circ} \mathrm{C}$ under $5 \% \mathrm{CO}_{2}$.

Daily monitoring of turbidity

\begin{tabular}{|c|l|l|l|l|l|l|l|}
\hline & Day 2 & Day 4 & Day 6 & Day 8 & Day 10 & Day 12 & Day 14 \\
\hline 1 $^{\text {st }}$ cartridge & & & & & & & \\
\hline $2^{\text {nd }}$ cartridge & & & & & & & \\
\hline $3^{\text {rd }}$ cartridge & & & & & & & \\
\hline $\begin{array}{c}\text { Negative } \\
\text { control }\end{array}$ & & & & & & & \\
\hline $\begin{array}{c}\text { Positive } \\
\text { control }\end{array}$ & & & & & & \\
\hline
\end{tabular}

Date, name, position and signature of a qualified person

Fig. 1 Datasheet for microbiological qualification of Unidose ${ }^{\oplus}$ 
(TS) agar (Becton-Dickinson) before and after biodecontamination following internal procedures (intensive and precautious cleaning with a disinfectant detergent solution based on a N-(3-aminopropyl)-N-dodecylpropane-1, 3-diamine, didecyldimethylammonium chloride and propan-2-ol mixture), we characterized the surface biocontamination. Agars were incubated at $37{ }^{\circ} \mathrm{C}$ under $5 \% \mathrm{CO}_{2}$ for 5 days and colonies were then counted $\left(\mathrm{CFU} / 25 \mathrm{~cm}^{2}\right)$. Further identification was realized by our Microbiology Department. Positive and negative control agars were prepared and incubated simultaneously. Surface biocontamination assessment was operated by a qualified radiopharmacist, repeated three times each session and followed-up monthly for 6 months. Results were expressed as mean $\pm \mathrm{s}_{\mathrm{d}} \mathrm{CFU} / 25 \mathrm{~cm}^{2}$.

\section{Microbiological validation - media fill tests}

MFTs were carried out to evaluate the whole filling process sterility at the end of a routine PET session. To achieve those adapted MFT, a sealed, sterile TS broth vial (Becton-Dickinson) was put in place of the leaded multidose radiopharmaceutical vial, then the dispensing process was initiated. The resulting cartridges were aseptically transferred to TS broth tubes (Becton-Dickinson) and according to the European Pharmacopoeia specifications, placed for incubation 7 days at room temperature and then 7 days at $37^{\circ} \mathrm{C}$ under $5 \% \mathrm{CO}_{2}$, with daily monitoring of turbidity. Positive and negative control solutions were prepared and incubated simultaneously. MFT was operated by a qualified radiopharmacist, repeated three times each session and followed-up monthly for 6 months. Results were expressed as mean $\pm s_{d}$ number of contaminated tubes.

\section{Operator qualification (OpQ)}

Operators were individually trained and evaluated by one and only qualified radiopharmacist. A qualification scale inspired from the NIH Competencies Proficiency Scale (Fig. 2) was established and focused on evaluating the operators' knowledge of the equipment, materials, software and accessories, their knowledge of our internal procedures regarding the ADS cleaning, setup, single dose dispensing process, backup mode, radioprotection, and their ability to apply these procedures during a PET session. The operators were considered as qualified if the score was equal to or superior than 95/100. They were briefed on our procedures and general good practices when appropriate.

\section{Statistics}

Surface microbiological contamination data were submitted to a two-tailed Wilcoxon matched-pairs signed rank test. $P \leq 0.05$ indicated significance.

\section{Results}

Microbiological validation - surface qualification

A minor microbiological contamination was found at the first assessment on TS agars sampled from the carousel $\left(7.1 \pm 1.5 \mathrm{CFU} / 25 \mathrm{~cm}^{2}\right)$ and was identified as classical handborne microflora (Micrococcus luteus and Staphylococcus sp.). Investigating for the biocontamination origin, the cap used for daily sterile filter sealing tests was found contaminated by the same microflora $\left(13.2 \pm 3.8 \mathrm{CFU} / 25 \mathrm{~cm}^{2}\right)$. We consequently adapted our daily biodecontamination procedure to include this instrument and renewed advice 


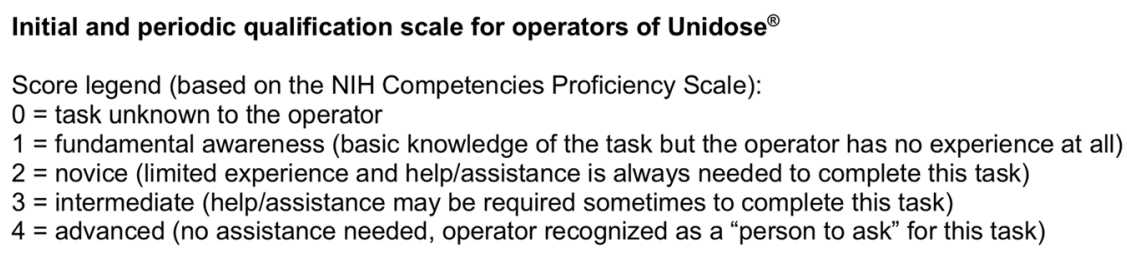

Name and position of the operator:

Date:

\begin{tabular}{|c|c|c|}
\hline Task & Skills & Score \\
\hline 1 & Where to find the procedures & \\
\hline 2 & Read and signed the procedures & \\
\hline 3 & $\begin{array}{l}\text { How to switch on the computer and dispenser if needed, and how to open the } \\
\text { Unidose }{ }^{\circledR} \text { software }\end{array}$ & \\
\hline 4 & How to realize the daily controls and biodecontamination & \\
\hline 5 & Instruments and manipulation rules (asepsis) & \\
\hline 6 & How to place the tubing set & \\
\hline 7 & $\begin{array}{l}\text { How to set up a multidose radiopharmaceutical drug vial in the side unit, depending } \\
\text { on the drug product and its supplier }\end{array}$ & \\
\hline 8 & How to transfer the active solution into the reservoir & \\
\hline 9 & $\begin{array}{l}\text { How to verify patient's data in Unidose }{ }^{\circledR} \text { software (medical prescription, body weight } \\
\text { or WMI, age) }\end{array}$ & \\
\hline 10 & How to modify the default injection time and/or the syringe activity if required & \\
\hline 11 & How to initiate the cartridge filling and where to observe the filling steps if needed & \\
\hline 12 & How to collect the cartridge in the injection shield, respectful to radioprotection & \\
\hline 13 & Medical devices needed to inject a patient & \\
\hline 14 & How to set up an injection kit with a filled cartridge & \\
\hline 15 & How to inject the drug product to a patient & \\
\hline 16 & How to realize the appropriate traceability (software \pm patient file) & \\
\hline 17 & $\begin{array}{l}\text { How to transfer the drug product solution from the dispenser reservoir to the initial } \\
\text { vial if needed }\end{array}$ & \\
\hline 18 & How to store a cartridge and how to follow its decay if needed & \\
\hline 19 & How to attribute a stored cartridge to a patient & \\
\hline 20 & How to terminate a production & \\
\hline 21 & How to change the tubing set when a new drug product is used & \\
\hline 22 & How to clean and biodecontaminate the medical devices used & \\
\hline 23 & How to deal with radioactive wastes & \\
\hline 24 & How to troubleshoot and which person to contact in case of unsolved issue. & \\
\hline 25 & How to proceed in downgraded mode & \\
\hline
\end{tabular}

Operator validation

Name, position and signature of the qualified auditor:

Fig. 2 Initial and periodic qualification scale for operators of Unidose ${ }^{\circledast}$

to the operators on this procedure knowledge and general hygiene procedures. Since then, all the agars realized on 7 independent sessions have stayed in line with ISO classification recommendations on the three areas of interest. The modified biodecontamination procedure significantly reduced microbiological contamination on the carousel $(2.14 \pm 2.34$ $\mathrm{CFU} / 25 \mathrm{~cm}^{2}$ before, $0.286 \pm 0.49 \mathrm{CFU} / 25 \mathrm{~cm}^{2}$ after biodecontamination, $P=0.0312, n=7$ ), on the reservoir surface $\left(1.57 \pm 1.13 \mathrm{CFU} / 25 \mathrm{~cm}^{2}\right.$ before, $0.14 \pm 0.39 \mathrm{CFU} / 25 \mathrm{~cm}^{2}$ after biodecontamination, $P=0.0312, n=7)$ and on the gloves $\left(12.9 \pm 8.43 \mathrm{CFU} / 25 \mathrm{~cm}^{2}\right.$ before, $1.86 \pm 2.03 \mathrm{CFU} / 25 \mathrm{~cm}^{2}$ after biodecontamination, $P=0.0156, n=7$ ), as shown in Fig. 3 .

\section{Microbiological validation - media-fill tests}

No microbiological contamination was detected in any TS tube. The media fill test resulted in clear, sterile cartridges $(n=7)$, validating the process sterility. 

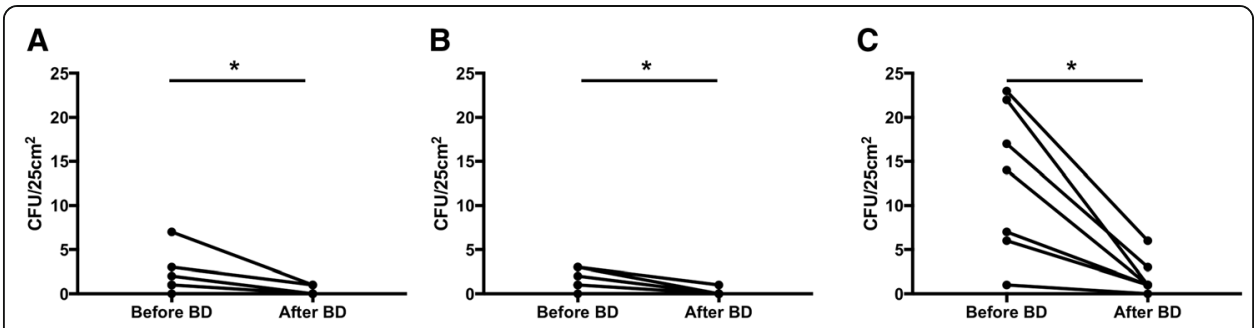

Fig. 3 The importance of an adequate biodecontamination on microbiological qualification. Microbiological qualification results on 3 areas of interest: the carousel with ISO4.8 specifications (a), the reservoir surface (b) and the gloves (c) both with ISO7 specifications, before and after biodecontamination (BD). ${ }^{*} P<0.05, n=7$; two-tailed Wilcoxon matched-pairs signed rank test.

\section{Operator qualification}

Two radiopharmacists, 3 pharmacy residents, 1 pharmacy technician and 13 technologists underwent OpQ by a qualified, experienced radiopharmacist. At the end of $\mathrm{OpQ}$, the staff was specifically made aware of daily biodecontamination importance and general hygiene procedures. The staff successfully qualified with a mean score of $97 \pm 2 / 100$, reflecting its adequate knowledge and understanding of procedures and its ability to apply these with only a few or no assistance needed at all following trainings and briefings. As OpQ will be repeated on a yearly basis, personal results are archived to enable a follow-up of the competencies from a year to another.

\section{Discussion}

In most European countries, it is the radiopharmacist's responsibility to ensure aseptic conditions for preparing or manufacturing injectable drug products and for their dispensation, including radiopharmaceutical drugs whether the manufacturing/preparation process is automated or not (Decristoforo and Patt 2016). Regarding PET ADS, a complete initial qualification is classically carried out by the manufacturer or the distributor once the equipment is installed (Table 1): in our department, the initial performance qualification was negative for microbiological contamination of air $\left(<1 \mathrm{UFC} / \mathrm{m}^{3}\right)$ and surfaces $\left(<1 \mathrm{UFC} / 25 \mathrm{~cm}^{2}\right)$. Still, the annual maintenance includes particular qualification, but excludes microbiological qualification with no specific recommendation from the manufacturer.

After setting up our internal qualification plan, we highlighted a minor microbiological contamination on our first assessment, that corrective actions solved and made finally the results conform to GMP. We therefore decided to brief our operators once a month on microbiological control results, hygiene and good practices, with the support of the present case illustrating the biodecontamination efficiency.

Table 1 Initial Trasis Unidose ${ }^{\circledast} \mathrm{IQ} / \mathrm{OQ} / \mathrm{PQ}$

\begin{tabular}{lll}
\hline IQ & OQ & PQ \\
\hline - Setup check-list & - Labels data consistency & - Requested activity vs filled activity precision \\
- Network configuration & - Air bubble size & - Internal dose calibrators \\
- Trainings & - Cartridge closure & - precision vs external calibrated dose calibrator \\
& - Particular qualification \\
& - Microbiological qualification (externalized) \\
& - External dose rate \\
& & PC/Unidose bridge \\
\hline
\end{tabular}


According to GMP, active air monitoring should be performed additionally to surface monitoring to complete the microbiological qualification. Yet, active air monitoring in Trasis Unidose $e^{\oplus}$ is very limited as the space for positioning an air impactor to sample the classified areas, is very limited itself. The manufacturer comes with its own specifically-designed air impactor system handler for the planned yearly maintenance, but such a device is not sold with the ADS so self-qualification seems hazardous when positioning classical air impactor systems. That's precisely the reason why we decided not to recommend such a control, but rather to introduce an adapted MFT for the ADS: although not designed to assess any ISO classification area, this MFT not only validates the open-system step for cartridge filling, but also validates the whole-process of cartridge-manufacturing sterility, complementary to surface monitoring.

More generally for any ADS, a monthly microbiological control of surfaces and instruments should be recommended, as well as a media-fill test that should be repeated after each maintenance and/or modification of the dispensing process, in line with the recent EANM guidelines on validation and qualification of processes and operators (Todde et al. 2017).

An initial and yearly operator's qualification should be established including the whole ADS applications. Regular training and information should be dispensed to the operators, regarding the importance of properly carrying out the biodecontamination of surfaces and instruments.

\section{Conclusions}

The automation of PET monodose conditioning process still implies human intervention for material preparation and manual biodecontamination. This study illustrates that initial and periodic qualification of the environment and the conditioning process of ADS, including regular microbiological qualification and operators' qualification, are needed to meet specifications and answer quality standards, in the interest of the patient's safety.

\footnotetext{
Abbreviations

ADS: Automated dispensing system; CFU: Colony-forming unit; EANM: European Association of Nuclear Medicine; FDA: Food and Drug Administration; GMP: Good Manufacturing Practices; HEPA: High Efficiency Particulate Air; IQ: Installation qualification; ISO: International Organization for Standardization; MFT: Media-fill test; NIH: National Institutes of Health; OpQ: Operator qualification; OQ: Operational qualification; PET: Positron-emitting tomography; PIC/ S: Pharmaceutical Inspection Co-operation Scheme; PQ: Performance qualification; TS: Tryptic-soy
}

Acknowledgements

Not applicable.

Authors' contributions

TM and PG initiated the study. TM, AM, CF, ET, AG, PG performed the experiments. TM, AM, CF, ET and PG analyzed and interpreted the data. TM, AM and PG wrote the manuscript. PG and BG reviewed the manuscript. All authors read and approved the final manuscript.

Funding

Nothing to declare.

Availability of data and materials

All data generated or analyzed during this study are included in this published article.

Ethics approval and consent to participate

Not applicable.

Consent for publication

Not applicable. 
Competing interests

The authors declare that they have no competing interests.

\section{Author details}

${ }^{1}$ Radiopharmacie Hôpital Nord AP-HM, Marseille, France. ${ }^{2}$ Radiopharmacie Hôpital Timone AP-HM, Marseille, France. ${ }^{3}$ CERIMED, CNRS 2012, Aix-Marseille Université, Marseille, France. ${ }^{4}$ C2VN, INRA 1260, INSERM 1263, Aix-Marseille Université, Marseille, France.

Received: 8 March 2019 Accepted: 24 May 2019

Published online: 13 June 2019

References

Aerts J, Ballinger JR, Behe M, Decristoforo C, Elsinga PH, Faivre-Chauvet A, et al. Guidance on current good radiopharmacy practice for the small-scale preparation of radiopharmaceuticals using automated modules: a European perspective. J Label Compd Radiopharm. 2014;57:615-20. https://doi.org/10.1002/jlcr.3227SMASH.

Covens P, Berus D, Vanhavere F, Caveliers V. The introduction of automated dispensing and injection during PET procedures: a step in the optimisation of extremity doses and whole-body doses of nuclear medicine staff. Radiat Prot Dosim. 2010; 140:250-8. https://doi.org/10.1093/rpd/ncq110SMASH.

Decristoforo C, Patt M. Are we "preparing" radiopharmaceuticals? EJNMMI Radiopharm Chem. 2016;1:12. https://doi.org/10. 1186/s41181-016-0011-7SMASH.

EudraLex. Volume 4 - Good Manufacturing Practice (GMP) guidelines - European Commission. 2015. https://ec.europa.eu/ health/documents/eudralex/vol-4_fr. Accessed 27 Dec 2018.

Media Fills for Validation of Aseptic Preparations for Positron Emission Tomography (PET) Drugs. Food and Drug Administration CDER CGMP. 2016. http://academy.gmp-compliance.org/guidemgr/files/UCM273766.PDF. Accessed 27 Dec 18.

ISO 14644-1:2017(en), Cleanrooms and associated controlled environments — Part 1: Classification of air cleanliness by particle concentration. 2017. https://www.iso.org/obp/ui/\#iso:std:iso:14644:-1:ed-2:v1:en. Accessed 27 Dec 2018.

Lecchi M, Lucignani G, Maioli C, Ignelzi G, Del Sole A. Validation of a new protocol for ${ }^{18} \mathrm{~F}-\mathrm{FDG}$ infusion using an automatic combined dispenser and injector system. Eur J Nucl Med Mol Imaging. 2012;39:1720-9. https://doi.org/10.1007/s00259012-2174-0SMASH.

O'Doherty J, Woods E, Modde L, Mackewn J. Validation of an automated dose-dispensing system for 18F-FDG administrations and associated reduction in operator extremity dose. Nucl Med Commun. 2014;35:151-9. https://doi.org/10.1097/MNM. 0000000000000027SMASH.

$\mathrm{PIC/S}$ (n.d.)"Recommendations on Validation Master Plan, Installation and Operational Qualification, Non-sterile Process Validation, Cleaning Validation" https://www.picscheme.org/layout/document.php?id=152. Accessed 27 Dec 18.

Todde S, Peitl PK, Elsinga P, Koziorowski J, Ferrari V, Ocak EM, et al. Guidance on validation and qualification of processes and operations involving radiopharmaceuticals. EJNMMI Radiopharm Chem. 2017;2:8. https://doi.org/10. 1186/s41181-017-0025-9SMASH.

\section{Publisher's Note}

Springer Nature remains neutral with regard to jurisdictional claims in published maps and institutional affiliations.

\section{Submit your manuscript to a SpringerOpen ${ }^{\circ}$ journal and benefit from:}

- Convenient online submission

- Rigorous peer review

- Open access: articles freely available online

- High visibility within the field

- Retaining the copyright to your article

Submit your next manuscript at $\boldsymbol{\Delta}$ springeropen.com 